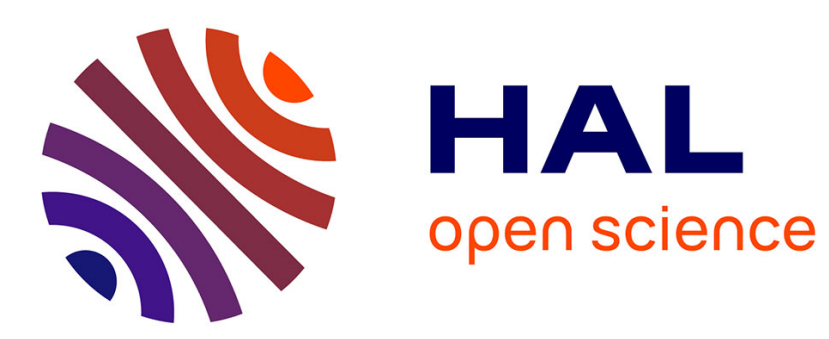

\title{
High-Reynolds shallow flow over an inclined sinusoidal bottom
}

\author{
Louis-Romain Plumerault, Dominique Astruc, Olivier Thual
}

\section{To cite this version:}

Louis-Romain Plumerault, Dominique Astruc, Olivier Thual. High-Reynolds shallow flow over an inclined sinusoidal bottom. Physics of Fluids, 2010, vol. 22, pp. 054110-1-054110-5. 10.1063/1.3407668 . hal-00960256

\section{HAL Id: hal-00960256 \\ https://hal.science/hal-00960256}

Submitted on 17 Mar 2014

HAL is a multi-disciplinary open access archive for the deposit and dissemination of scientific research documents, whether they are published or not. The documents may come from teaching and research institutions in France or abroad, or from public or private research centers.
L'archive ouverte pluridisciplinaire HAL, est destinée au dépôt et à la diffusion de documents scientifiques de niveau recherche, publiés ou non, émanant des établissements d'enseignement et de recherche français ou étrangers, des laboratoires publics ou privés. 


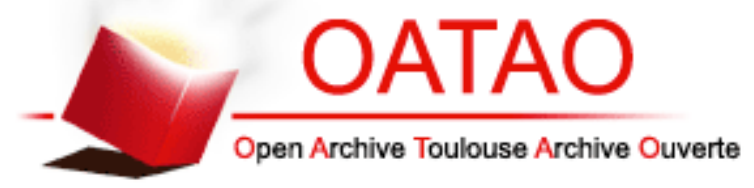

\section{Open Archive TOULOUSE Archive Ouverte (OATAO)}

OATAO is an open access repository that collects the work of Toulouse researchers and makes it freely available over the web where possible.

This is an author-deposited version published in : http://oatao.univ-toulouse.fr/ Eprints ID : 6709

To link to this article : DOI:10.1063/1.3407668

URL : http://dx.doi.org/10.1063/1.3407668

\section{To cite this version :}

Plumerault, Louis-Romain and Astruc, Dominique and Thual, Olivier High-Reynolds shallow flow over an inclined sinusoidal bottom. (2010) Physics of Fluids, vol. 22 (n 5). ISSN 1070-6631

Any correspondance concerning this service should be sent to the repository administrator: staff-oatao@inp-toulouse.fr 


\title{
High-Reynolds shallow flow over an inclined sinusoidal bottom
}

\author{
L.-R. Plumerault ${ }^{1,2}$, D. Astruc ${ }^{1,2}$, O. Thual ${ }^{1,2}$ \\ ${ }^{1}$ Université de Toulouse ; INPT, UPS ; IMFT, \\ Allée Camille Soula, F-31400 Toulouse, France \\ ${ }^{2}$ CNRS ; IMFT ; F-31400 Toulouse, France
}

March 11, 2010

\begin{abstract}
An experimental study of a turbulent free-surface shallow flow over an inclined sinusoidal bottom with a fixed corrugation amplitude is presented. A parametric analysis is performed by varying both the inclination angle and the Reynolds number. We show that a "Pulse-Waves" regime, dominant for Reynolds smaller than 4 000, coexists with a "Roll-Waves" regime, which becomes dominant above this value. The relative energy of the waves is quantified in the parameter space. At Reynolds numbers larger than 8 000, these wave instabilities disappear.
\end{abstract}

Keywords: inclined channel; corrugated bottom; Roll Waves; pulses. 


\section{Introduction}

Free-surface flows over an inclined flat bottom have been studied since the pioneering works of [1], [2] and [3]. These flows proved to be unstable to travelling waves perturbations. Both flows at large and small Reynolds numbers have been investigated. [2] led a basic experiment on the flow of water down an inclined wooden channel introducing the mechanism of surface instability of turbulent "Roll Waves" over a flat bottom previously revealed by [1]. Laminar Roll Waves exist too and have been initially investigated in viscous fluids by [3]. They arise in flows in which surface tension is the prominent force like thin film flows, as shown by [4] who reviews investigations on waves at the free surface of films falling vertically with a Reynolds number up to 1000.

More recently, [5] led theoretical investigations on the Roll-Wave instability in nonNewtonian fluids falling down over an inclined plane. [6] theoretically investigate the effect of a periodic bed topography on the Roll-Wave instability. With a shallow-water model, they found that a low-amplitude bottom topography tends to destabilize the flow, while it tends to stabilize it at larger amplitudes. Moreover, the theory that they expose predicts that Roll-Waves are unstable for Froude numbers above 2 whatever the perturbation amplitude.

In spite of this background, the problem of films flowing down disturbed bottoms seems to have motivated only little experimental work. Stationary regimes of a viscous liquid down an inclined channel with sinusoidal bottom have been documented by [7], with an hysteresis in transitions between humps and hydraulic jumps attributed to 
the surface tension. [8] and [9] carried an experiment on laminar film flowing down an inclined periodic wall including wall corrugations amplitude variations at Reynolds numbers up to 450 and at inclinations ranging from $2 \%$ to $27 \%$. They noticed that the basic 2D steady flow observed for low Reynolds numbers evolves for higher Reynolds numbers into a 3D steady flow. Therefore, the static substrate on which 2D progressive waves move depends on the Reynolds number. They both observe that a further increase of the Reynolds number leads to the disintegration of $2 \mathrm{D}$ progressive waves into surges of $3 \mathrm{D}$ horseshoe waves. Their experimental set up allows them to vary corrugation steepness from zero to $1 / 15$. They showed that an increase of the wall corrugation tends to regularize the waves spectrum while a clear frequency peak arises as the wall dimensionless amplitude increases.

On a theoretical field, [10], [11] and [12] developed a three-wave resonant theory in order to investigate the instability of incompressible free surface flows over sinusoidal bottom topography completing the work of [13] and [14].

In this paper, the attention is focused on turbulent, shallow and free-surface flows over an inclined sinusoidal bottom at Reynolds numbers ranging from 1000 to 8000 . A brief description of the experimental set-up is given in Section 2. Section 3 contains an analysis of two observed regimes of travelling waves that we denote by "Roll-Wave" and "Pulse-Wave" regimes. In Section 4, we show that these two regimes coexists and give an interpretation of the regime transition. A brief conclusion follows. 


\section{Experimental set-up}

A 12-m-long reclining open water channel with glass walls is used, of width $b=25 \mathrm{~cm}$.

A galvanized steel sheet with a sinusoidal profile is laid out on the channel bottom (Figure 1) with a fixed amplitude $a=0.75 \mathrm{~cm}$ and a wavelength $\lambda=7.6 \mathrm{~cm}$ for the corrugation. The inclination slope $I=\tan \theta$ ranges from $3 \%$ to $8.8 \%$ since the latter value is a technical upper bound and the regimes are not saturated enough under the former value. The flow rate $Q$ of water is controlled by a pump and can range from $0.09 \mathrm{l} / \mathrm{s}$ to $2.5 \mathrm{l} / \mathrm{s}$.

The water free surface position is measured $9 \mathrm{~m}$ downstream from the beginning of the metal sheet using a shadowgraphy method. A spotlight illuminates the channel through a diffusive panel and a camera is placed at $5 \mathrm{~m}$ from the flume on the other side. This camera has a $1280 \times 256$ pixels resolution and its acquisition frequency is set to 20 Hertz. The shooting field covers about $5.5 \lambda$ with a 30 pixels/cm resolution. Each acquisition, of about 1500 images, lasts for about 75 s. A contour recognition algorithm, based on the binarisation of the pixel gray level, has been used in order to measure the position of the water free surface. The precision of this measurement, particularly in the turbulent regimes, is the same as the one of a human eye.

In this experiment, the fixed dimensionless parameter are the steepness $S=$ $2 a / \lambda \sim 0.2, H=2 a\left(g / \nu^{2}\right)^{1 / 3} \sim 321$, where $g=9.81 \mathrm{~m} / \mathrm{s}^{2}$ is the gravity acceleration and $\nu=10^{-6} \mathrm{~m}^{2} / \mathrm{s}$ the water dynamic viscosity, the dimensionless roughness $R g=K^{3}\left(\nu / g^{5}\right)^{1 / 3} \sim 114$ where $K=80 \mathrm{~m}^{1 / 3} \mathrm{~s}^{-1}$ is the Strickler number of a galvanizedsteel bottom $([15])$ and the Bond number $B o=(\rho / \sigma) g R^{2} \sim 51$ where $\rho=998 \mathrm{~kg} / \mathrm{m}^{3}$ 
is the water density, $\sigma=.073 \mathrm{~N} / \mathrm{m}$ the water surface tension and $R=\lambda^{2} /\left(4 \pi^{2} a\right)$ is the smallest curvature radius of the bottom corrugation. The two control parameters varied in this experiment are thus the Reynolds number $R e=Q /(b \nu)$ and the slope $I$. The described regime are not sensitive to the upstream water height since the spatial transitory is ignored. Adding to the fact that we only consider two-dimensional flows, there are no more dimensionless control parameters to consider.

A Froude number $F r=U / \sqrt{g h \cos \theta}$, where $U$ is a velocity and $h$ a height, can be defined in several ways for this experiment, each one of them leading to a function of the six dimensionless numbers $S, H, R g, B o, R e$ and $I$. Since the slope $I=\tan \theta$ is small, we suppose that $\cos \theta \approx 1$ in Froude number definitions. For example, Froude numbers can be defined by referring to a flat bottom (no corrugation) such as $F r_{v}=R e I / 2$, based on the viscous solution ([7]), or $F r_{n}=U_{n} / \sqrt{h_{n} g}=R e^{1 / 10} R_{g}^{3 / 10} I^{9 / 20}$, based on the turbulent normal flow ([13]) given by $Q=h_{n} U_{n} b$ and the Manning-Strickler parametrisation $U_{n}=K h_{n}^{2 / 3} I^{1 / 2}$. In this paper, we do not refer to any flat bottom flows and we define our Froude number by $F r=U_{a} / \sqrt{2 a g}=\operatorname{Re} H^{-3 / 2} \sim \operatorname{Re} / 5754$, assuming that $2 a$ is the "reference depth" of the flow and thus $U_{a}=Q /(2 a b)$ its "reference velocity". The choice of a Froude number definition only matters when dealing with theoretical interpretation of the flow regimes, as done in this paper with the triadic resonance between the bottom corrugation and two counter-propagating surface waves. 


\section{Observation of two wave regimes}

For most of the explored flow rate $Q$ and slope $I$, the upstream part of the flow is transitory. Regimes grow over this part and saturate before the location where the observations are performed. We focus here on two qualitatively different types of twodimensional (2D) traveling waves propagating downwards. For Reynolds numbers less than about 4 000, a Pulse-Wave type regime is observed with a wavelength of the order of a few $\lambda$. For Reynolds numbers in the 4 000-8 000 range, Roll-Wave type long waves are prominent. Since no waves are observed for higher Reynolds, we only describe these two wave regimes.

\subsection{Roll-Wave regime}

The Roll-Wave regime is characterized by long surface waves propagating downstream as shown in Figure 2. The plot of the free-surface elevation at different times exhibits a celerity of about $0.6 \mathrm{~m} / \mathrm{s}$ (Figure $2 \mathrm{a}$ ). The energy density, obtained from the Fourier transforms of the free surface elevation and their average on several fixed points, equally distributed in space, exhibits a low frequency at about $0.4 \mathrm{Hertz}$ (Figure 2b). The snapshots of the waves passing in the field of the camera exhibit a front propagating on an almost dry bottom (Figure 2c) .

In the range of slopes that have been explored (up to $I=8.8 \%$ ), we observe celerity ranging from $0.6 \mathrm{~m} / \mathrm{s}$ to $1 \mathrm{~m} / \mathrm{s}$, wavelengths ranging from 14 to 40 times the bottom wavelength $\lambda$, frequency peaks varying in the spectral band $[0,1]$ Hertz and water depth

of a few centimeters. These waves are thus shallow-water waves and their features are 
similar to the ones of classical Roll Waves observed on flat rough bottoms. In addition to the propagation of the hydraulic bore and turbulent distortions, we observe that the free surfaces exhibit spatial undulations in phase with the bottom corrugation at the left of the bore. This shows that the flows is super-critical there, in the frame of the laboratory $([15])$.

\subsection{Pulse-Wave regime}

The Pulse-Wave regime is characterized by high-frequency waves propagation downstream as shown in Figure 3. The plot of the free surface position at different times exhibits a celerity of about $0.3 \mathrm{~m} / \mathrm{s}$ (Figure 3a). The energy density exhibits a frequency at about 2.2 Hertz (Figure 3b), which corresponds to localized structures that cross the field of the camera with a spatial period wandering around $3 \lambda$ (Figure $3 \mathrm{c}$ ). These waves look like cnoidal waves $([16])$.

In the range of slopes that we have explored, we observe velocities ranging from $0.15 \mathrm{~m} / \mathrm{s}$ to $0.30 \mathrm{~m} / \mathrm{s}$, wavelengths ranging from 3 to 5 times the bottom wavelength $\lambda$ and water depth less than two centimeters. In addition to the frequencies associated to the travelling pulses in the $[1.8,2.5]$ Hertz range, we observe a frequency peak in the $[1.5,1.8]$ Hertz range. Through careful analyses of the free surface evolution, we can attribute these last frequencies to a stationary oscillation associated to the sloshing of the fluid between two bottom hills. We suspect that this seiche oscillation plays an important role in the nonlinear interaction between resonant modes of the instability. 


\section{Analyses of the two wave regimes}

Beyond the visual observation of the flow, a detailed analysis of the recorded signals shows that the two wave regimes coexist for fixed values of the slope and the flow rate. We then give a theoretical interpretation of this hysteretic transition between regimes.

\subsection{Regime coexistence at fixed parameters}

A parametric study of the flow regimes in the $(I, R e)$ parameter plane is presented in Figure 4. At high Reynolds numbers $R e$, a stationary turbulent flow with no waves and water heights greater than about five centimeters is observed. The limiting dotted line (...) plotted at the top of the figure has been drawn by visual observations of the flow as precisely as allowed by the experiment.

Although the Roll-Wave regime dominates for moderate value of $R e$ and the PulseWave regime dominates for low $R e$, we can show that the two regimes coexist in a wide range of Reynolds numbers. To this end, we plot, in Figure 5, the energy content of the surface elevation signal in the $[0,1]$ Hertz and $[1,3]$ Hertz bands, which respectively characterize the Roll-Wave and the Pulse-Wave regimes.

The energy of the Pulse-Wave mode increases with the slope with a saturation at $I=6 \%$, which is probably due to the fact that the measure is not performed downstream enough for the low inclination cases to be fully developed. Contrarily to the energy of the Pulse-Wave mode, the energy of the Roll-Wave mode is strongly

dependent on the Reynolds number $R e$, increasing with it. For $R e \geq 6$ 000, there is no more peak in the Pulse-Wave energy band, and we no longer plot its mean energy 
density for this reason. A saturation of the Roll-Wave energy band is observed for $R e \geq 4000$ at high $I$, for $R e \geq 7000$ at low $I$, and for $I \geq 6 \%$ at high $R e$. From theses curves, the limit of equal mode energy is computed and plotted as a dashed (- -) line on Figure 4.

In Figure 6, the barycentric frequency weighted for each of the spectral bands representative of the two wave regimes are plotted as a function of $R e$ for several values of $I$. The Roll-Wave mode low frequency seems to be almost constant in the $0.5 \pm 0.1$ Hertz range while the Pulse-Wave mode higher frequencies decrease with $R e$. These frequencies exhibit only small variations with the slope $I$.

\subsection{A triadic resonance interpretation}

The identification of our Pulse-Wave regime seems to be new. We think that [9], although with a smaller steepness $S$, were in presence of it. However they did not identify it as being different from the "Roll Waves", which they denoted by "traveling pulses" (we have chosen to use the word "pulse" for the other waves). Indeed, even if it is not what they focused on, one can see, from the top of their figure 11a for $I=9.45 \%$ and $R e=76$, a secondary wave type, whose wavelength is four or five times the bottom wavelength, which seems to be Pulse Waves as defined in the present work.

One interpretation of our Pulse-Wave regime could be based on the triadic resonance between two counter-propagating surface waves and the sinusoidal bottom corrugation. The theoretical foundation of this mechanism can be found in [13], [10] or [11]. If $c_{a}=\sqrt{2 a g}$ is the "reference phase velocity" of the shallow surface waves relative to the "reference velocity" $U_{a}=Q /(2 a b)$, a downward wave of wavelength $\lambda_{+}$and an 
upward wave of wavelength $\lambda_{-}$are in triadic resonance with the bottom corrugation when the following relations are satisfied $([10])$ :

$$
\frac{1}{\lambda_{+}}+\frac{1}{\lambda_{-}}=\frac{1}{\lambda} \quad \text { and } \quad \frac{c_{a}+U_{a}}{\lambda_{+}}=\frac{c_{a}-U_{a}}{\lambda_{-}}
$$

Positive solutions $\lambda_{+}=2 \lambda /(1-F r)$ and $\lambda_{-}=2 \lambda /(1+F r)$ are obtained if the Froude number $\operatorname{Fr}=U_{a} / c_{a}$ is less than one. For the value $R e=1440$ of the Pulse Waves of Figure 3, the value $F r \sim 0.25$ leads to $\lambda_{+} \sim 2.7 \lambda$, which is close the observed wavelength between two Pulse-Wave crests, and to a frequency $f=\left(c_{a}+U_{a}\right) / \lambda_{+} \sim$ $2.4 \mathrm{~Hz}$ which is close to the experimental value. This interpretation is also consistent with the fact that, as indicated by Figure 5, no Pulse Wave is observed beyond $R e \sim$ 6 000, which corresponds the $F r=1$ threshold.

Our experiment has shown that the observed Pulse Waves are unstable to the development of Roll Waves as shown by Figure 5. For Re between 1000 and 4000 , these Roll Waves are present but with a weak energy. For Re between 4000 and 6000 , Pulse Waves are present in the tails of the Roll Waves.

\section{Conclusion}

An experimental study of an unstable turbulent free-surface flow over an inclined sinusoidal bottom has been carried out with a fixed corrugation amplitude. A parametric study in the plane of the slope $I$ and the Reynolds number Re has been performed. Two types of traveling waves have been distinguished. The first one is the well known Roll-Wave regime. The second one, denoted here by Pulse-Wave regime, has not been reported in the literature although [9] were in presence of it. Our parametric study 
has allowed to establish the ranges of parameters for which one type of wave is energetically predominant over the other. We have shown that the two regimes do coexist for a wide range of Reynolds number $R e$ for all the explored slopes $I$ and we have give an interpretation of the hysteretic transition between the two regimes based on the triadic resonance between surface waves. This interpretation shows that the Froude number Fr, built with the flow rate and the corrugation amplitude, is the pertinent dimensionless number for the transition between the two regimes.

\section{Acknowledgments}

The comments of a referee, leading to the interpretation of the results in term of triadic resonances, are thankfully acknowledged.

\section{References}

[1] V. Cornish. Waves of the sea and other water-waves. London T. Fisher Unwin, 1910.

[2] H. Jeffreys. The flow of water in an inclined channel of rectangular section. Phil. Mag. S.6., 49:293, 1925.

[3] P. L. Kapitza and S. P. Kapitza. Wave flow of thin viscous liquid films. Zh. Zxper. i Teor. Fiz., 19:105, 1949.

[4] H.-C. Chang. Wave evolution on a falling film. Ann. Rev. Fluid Mech., 26:103, 1994. 
[5] N. J. Balmforth and J. J. Liu. Roll waves in mud. J. Fluid Mech., 519(33), 2004.

[6] N. J. Balmforth and S. Mandre. Dynamics of roll waves. J. Fluid Mech., 514:1, 2004.

[7] A. Wierschem and N. Aksel. Hydraulic jumps and standing waves in gravity-driven flows of viscous liquids in wavy open channels. Physics of Fluids, 16(11):3868$3877,2004$.

[8] M. Vlachogiannis and V. Bontozoglou. Experiments on laminar film flow along a periodic wall. J. Fluid Mech., 457:133, 2002.

[9] K. Argyriadi, M. Vlachogiannis, and V. Bontozoglou. Experimental study of inclined film flow along periodic corrugations: The effect of wall steepness. Phys. Fluids, 18:012102, 2006.

[10] James T. Kirby. Current effects on resonant reflection of surface water waves by sand bars. Journal of Fluid Mechanics Digital Archive, 186(-1):501-520, 1988.

[11] V. Bontozoglou, S. Kalliadasis, and A. J. Karabelas. Inviscid free-surface flow over a periodic wall. Journal of Fluid Mechanics Digital Archive, 226(-1):189-203, 1991.

[12] J. P. McHugh. The stability of capillary-gravity waves on flow over a wavy bottom. Wave Motion, 16:23, 1992.

[13] A. J. Reynolds. Waves on the erodible bed of an open channel. Journal of Fluid Mechanics Digital Archive, 22(01):113-133, 1965. 
[14] C. S. Yih. Instability of surface and internal waves. Adv. Appl. Mech., 16:349, 1976.

[15] V. T. Chow. Open-channel hydraulics. McGraw-Hill, 1959.

[16] R. L. Wiegel. A presentation of cnoidal wave theory for practical application. Journal of Fluid Mechanics Digital Archive, 7(02):273-286, 1960. 


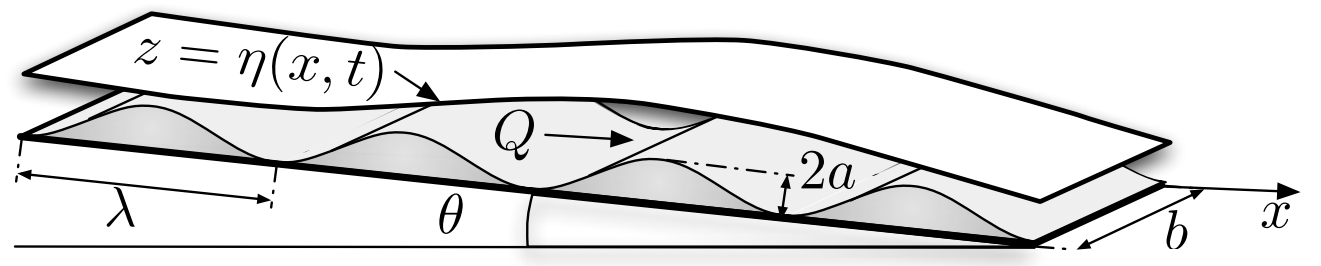

Figure 1: Free surface flow over an inclined nearly sinusoidal bottom. 

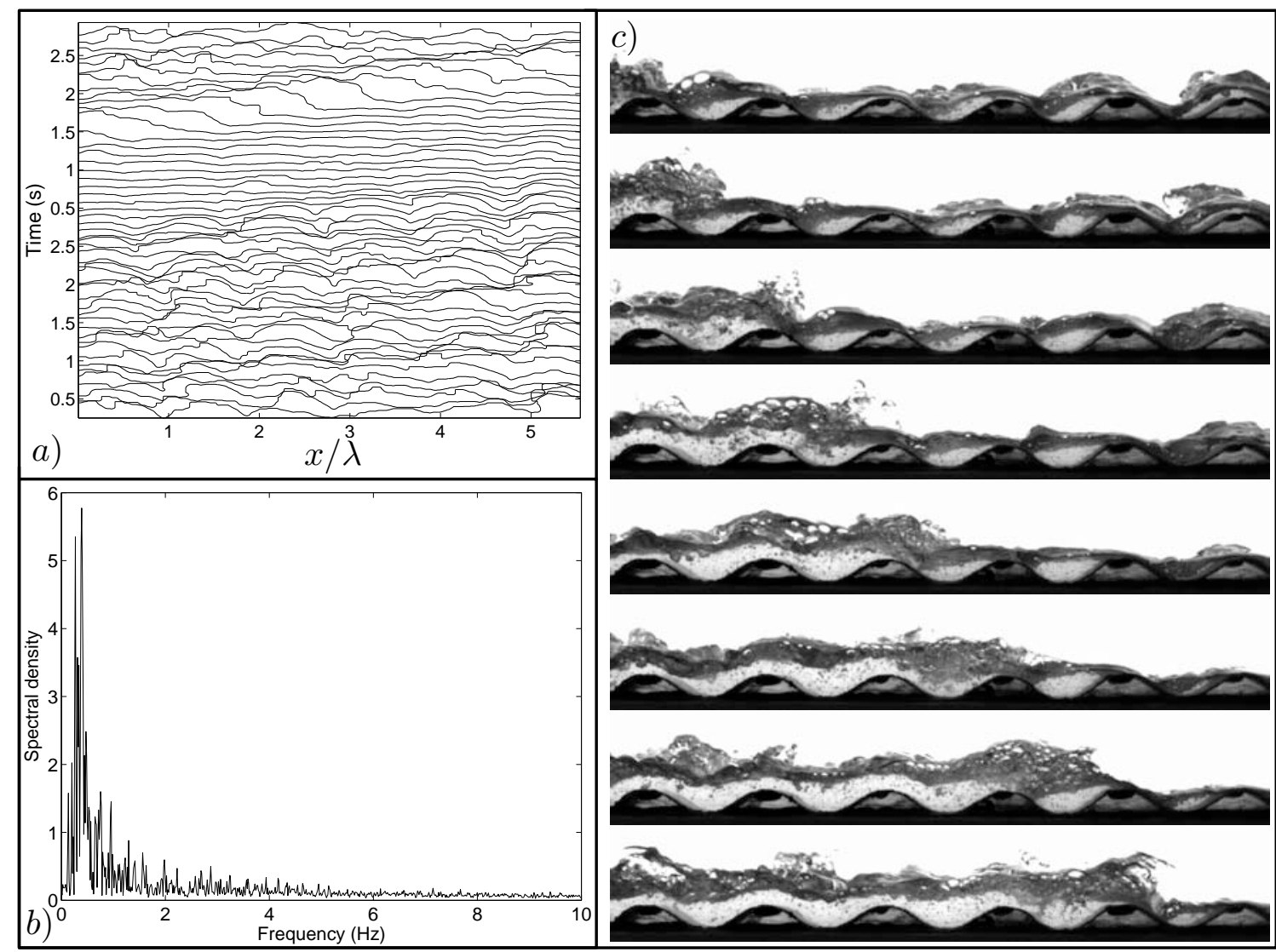

Figure 2: Roll-Wave regime for $R e=8040$ and $I=8.8 \%$ (enhanced online). a) Free surface profile at successive times. b) Spectral energy density at a fixed point. c) Snapshots at successive times (top to down). 


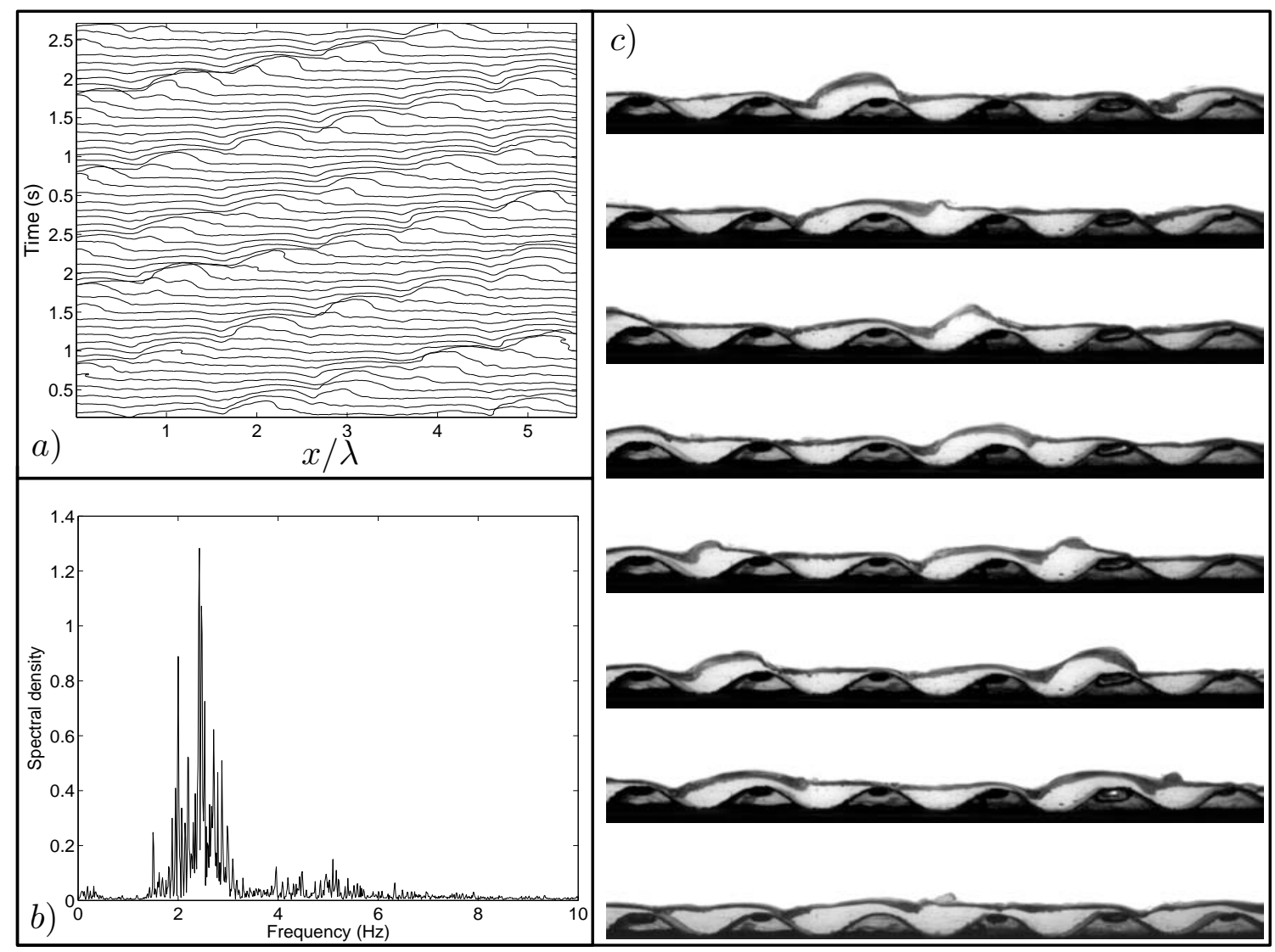

Figure 3: Pulse-Wave regime for $R e=1440$ and $I=8.8 \%$ (enhanced online). a)

Free surface profile at successive times. b) Spectral energy density at a fixed point. c)

Snapshots at successive times (top to down). 


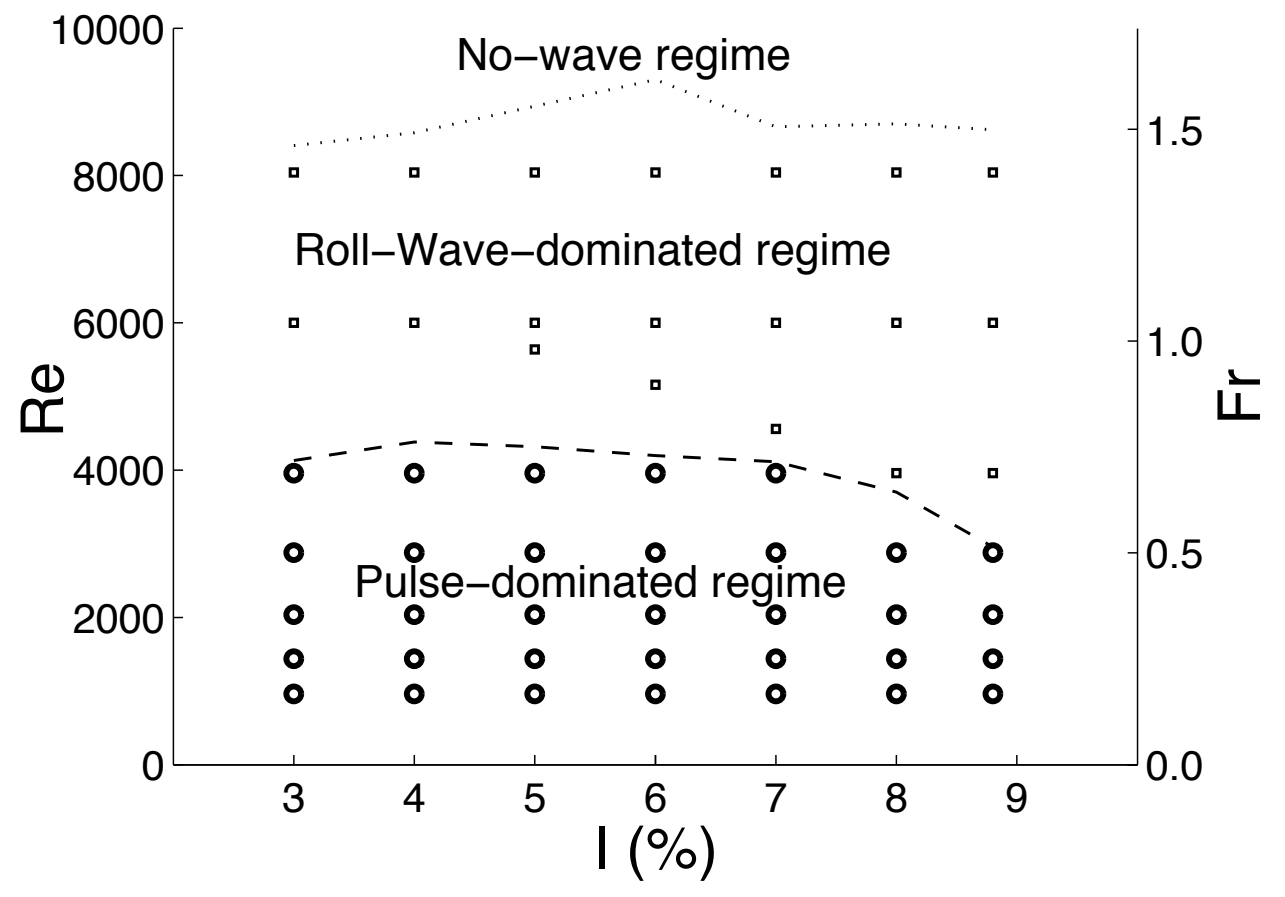

Figure 4: Free surface waves regimes in the $(I, R e)$ plane: Pulse-Wave regime (o), Roll-Wave regime (口). The Froude number is defined by $\mathrm{Fr}=\mathrm{Re} / 5754$. 


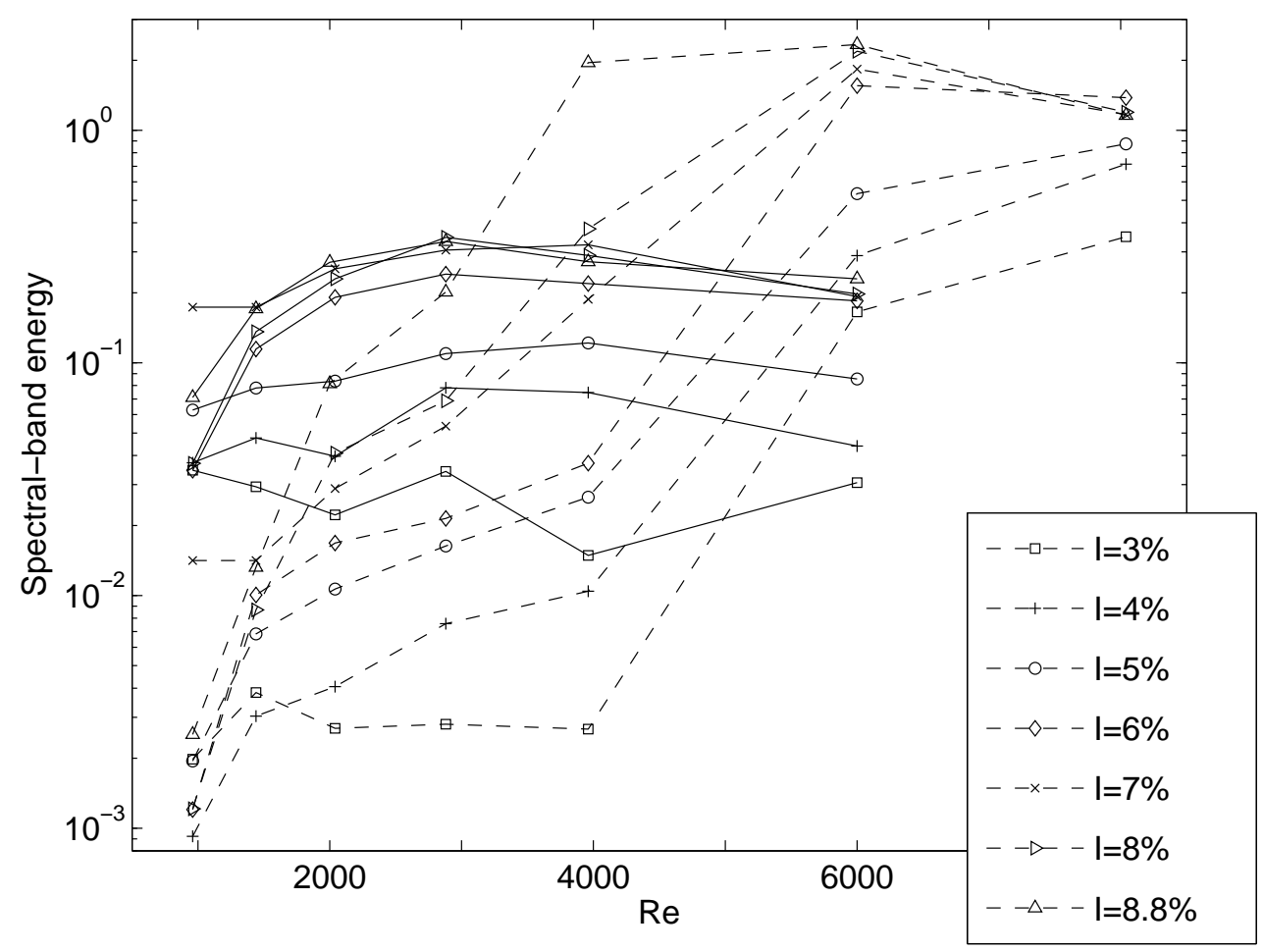

Figure 5: Logarithm of the mean energy density of the surface elevation signal for the spectral bands [0,1] Hertz (- -) and [1,3] Hertz (-) as function of Re for different values of the slope $I$. 


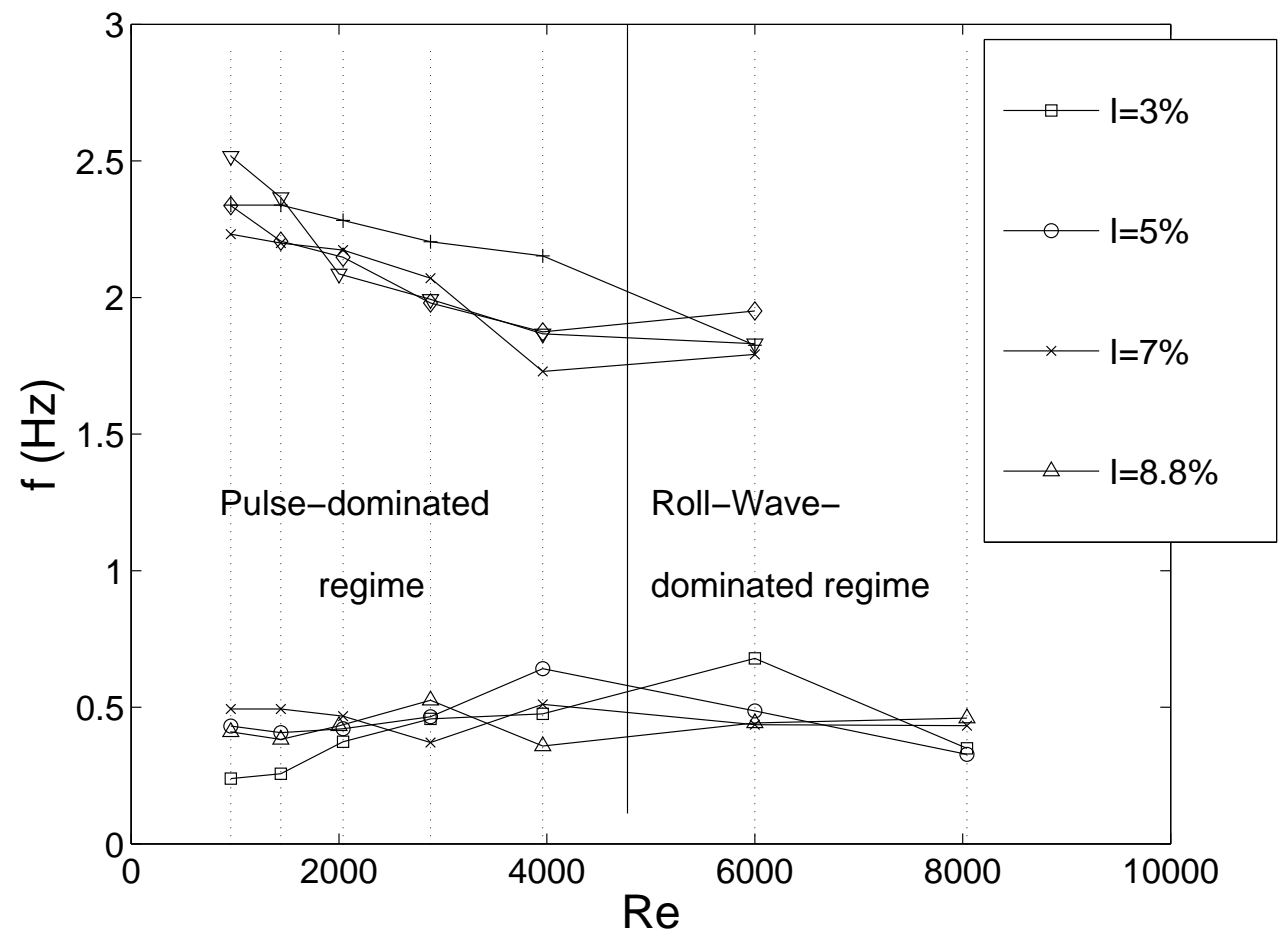

Figure 6: Barycentric frequency weighted by temporal spectral density for each inclination angle over the ranges [0,1] Hertz and [1,3] Hertz. The vertical line corresponds to the limit (dashed line) in Figure 4. 